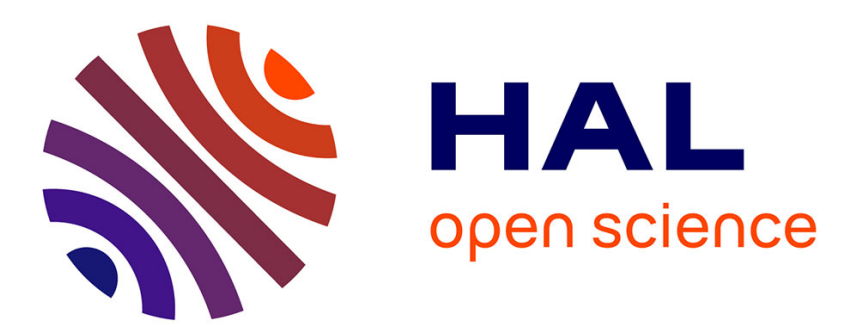

\title{
Performance evaluation of organoclays for the amoxicillin retention in a dynamic context
}

\author{
Régis Guégan, Lydie Le Forestier
}

\section{To cite this version:}

Régis Guégan, Lydie Le Forestier. Performance evaluation of organoclays for the amoxicillin retention in a dynamic context. Chemical Engineering Journal, 2021, 406, pp.126859. 10.1016/j.cej.2020.126859 . insu-02931496

\section{HAL Id: insu-02931496 https://hal-insu.archives-ouvertes.fr/insu-02931496}

Submitted on 7 Sep 2020

HAL is a multi-disciplinary open access archive for the deposit and dissemination of scientific research documents, whether they are published or not. The documents may come from teaching and research institutions in France or abroad, or from public or private research centers.
L'archive ouverte pluridisciplinaire HAL, est destinée au dépôt et à la diffusion de documents scientifiques de niveau recherche, publiés ou non, émanant des établissements d'enseignement et de recherche français ou étrangers, des laboratoires publics ou privés. 


\section{Journal Pre-proofs}

Performance evaluation of organoclays for the amoxicillin retention in a dynamic context

Régis Guégan, Lydie Le Forestier

PII:

S1385-8947(20)32987-9

DOI: https://doi.org/10.1016/j.cej.2020.126859

Reference: CEJ 126859

To appear in:

Chemical Engineering Journal

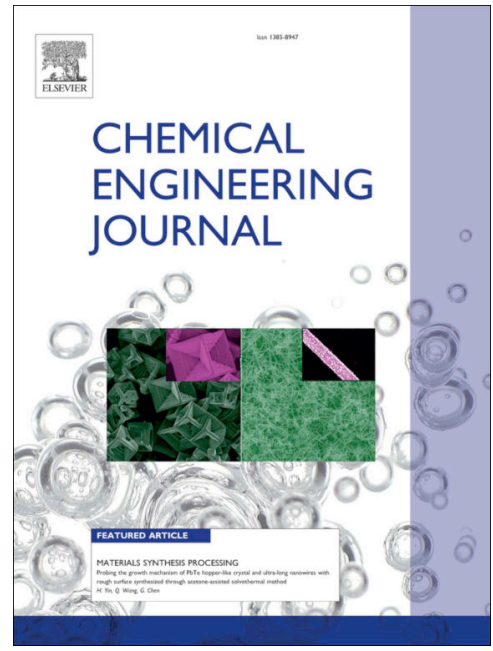

Received Date:

2 July 2020

Revised Date:

26 August 2020

Accepted Date:

27 August 2020

Please cite this article as: R. Guégan, L. Le Forestier, Performance evaluation of organoclays for the amoxicillin retention in a dynamic context, Chemical Engineering Journal (2020), doi: https://doi.org/10.1016/j.cej. 2020.126859

This is a PDF file of an article that has undergone enhancements after acceptance, such as the addition of a cover page and metadata, and formatting for readability, but it is not yet the definitive version of record. This version will undergo additional copyediting, typesetting and review before it is published in its final form, but we are providing this version to give early visibility of the article. Please note that, during the production process, errors may be discovered which could affect the content, and all legal disclaimers that apply to the journal pertain.

(C) 2020 Elsevier B.V. All rights reserved. 


\title{
Performance evaluation of organoclays for the amoxicillin
}

\section{retention in a dynamic context}

\author{
Régis Guégan ${ }^{\mathrm{a}, \mathrm{b} *}$, Lydie Le Forestier ${ }^{\mathrm{c}}$ \\ ${ }^{a}$ Global Center for Science and Engineering, Waseda University, 3-4-1 Okubo, Shinjuku-ku, \\ Tokyo 169-8555, Japan \\ ${ }^{b}$ Kagami Memorial Research Institute for Materials Science and Technology, Waseda \\ University, 2-8-26 Nishiwaseda, Shinjuku-ku, Tokyo 169-0051, Japan \\ ${ }^{c}$ Université d'Orléans, CNRS, BRGM, ISTO, UMR 7327, 45071 Orléans, France. \\ *Corresponding author: regis.guegan@aoni.waseda.jp or regis.guegan@univ-orleans.fr
}

\begin{abstract}
The hydraulic conductivity of diverse organoclays was determined through percolation experiments and compared to a raw Na-montmorillonite (Na-Mt). The incorporation of surfactants even at low content drastically changes the hydraulic conductivity with a large increase of about two order of magnitude in contrast to that of Na-Mt $\left(10^{-12} \mathrm{~m} \mathrm{~s}^{-1}\right)$. Batch kinetics and equilibrium adsorption experiments confirmed the proper affinity of organoclays to a zwitterion antibiotic: the amoxicillin (AMX) which was quickly adsorbed (at a time below $30 \mathrm{~min}$ ) at large amounts (up to $1.4 \times 10^{-3} \mathrm{~mol} \mathrm{~g}^{-1}$ ). However, in percolation conditions, the significant increase of the permeability led to a short interaction time between the organoclays and the pharmaceutical. In contrast to Na-Mt for which it took age to get only one drop of AMX, leachates, resulting of a percolation through organoclays, were collected for a time below $10 \mathrm{~min}$, not enough sufficient to ensure a proper removal of an antibiotic with concentration reduced by $5-80 \%$ of the initial solution.
\end{abstract}

Keywords: amoxicillin; organoclays; percolation experiments; adsorption; hydraulic conductivity 


\section{INTRODUCTION}

Clay minerals, in particular the swelling-type clays such as smectites, are commonly used as passive engineered barriers or liners in solid waste disposal landfills [1-5]. These materials, and especially montmorillonite (Mt), show remarkable hydration properties with macroscopic swelling and display a low conductivity for water on the magnitude of $10^{-11}-10^{-12} \mathrm{~m} \mathrm{~s}^{-1}$ which are essential to prevent any leaking of a pollution or reduce the transport of both organic and inorganic contaminants [1, 6-8]. Thus, these geomaterials also are used as filtration bed in water treatment facilities for the retention of many organic and inorganic pollutants.

The interactional mechanisms driving to the adsorption of the contaminants imply diverse mechanisms, but mainly non-directional electrostatic and ion-dipole interactions with the inorganic cations located within the interlayer space and in a lesser extent van der Waals forces that can be disrupted by a slight increase of a temperature or due to mechanical mixing. The design of these filters or equivalent percolators in both water facilities and/or private household applications respectively leans against a delicate balance between the diffusion regime controlling the quantity and rate of contaminants as well as the capacity of a system to uptake analytes. Thus, materials showing a low conductivity for water (or permeability) obviously represent promising engineering systems in waste disposal but are less effective in percolator systems with a leachate collection that could be fastidious.

Organoclays or clay modified by surfactants were suggested as amendments and even main materials for the above applications due to their singular adsorption properties to various kind of organic contaminants, including hydrophobic ones (i.e., organic contaminants with a $\log \mathrm{P}>0$ ) where raw clay minerals show their limits [1, 2, 4-6, 9-24]. Organoclays are prepared with surfactants intercalated within the interlayer space through cation exchange (electrostatic interaction) or by ion-dipole type with the compensating cations (in the case of nonionic surfactants) $[2,15,17,18,20]$. The resulting hybrid materials combine a large 
surface area, a hydrophobic character and an expansion of their interlayer space, conferring them the appropriate properties for the sorption of organic contaminants. Their adsorption efficiencies mainly depend on the nature of the surfactants intercalated as well as their density. Cationic organoclays (i.e. prepared with cationic surfactants) can be classified in two main groups: adsorptive clays, organoclays prepared with short alkyl chains such as tetramethyammonium (TMA) and organophilic clays including long alkyl chain surfactants such as hexadecyltrimethylammonium (HDTMA) [25-29]. The adsorptive clays or short chain organoclays and even those prepared with moderate chain surfactants show a limited interlayer space with the confinement of a monolayer of surfactants with regio-adsorptive sites. In contrast, organophilic clays display a hydrophobic environment or a hydrophobic partitioning phase generated by the intercalation of long alkyl chain surfactants, enlarging their interlayer space at large openings while enhancing the adsorption/removal or organic compounds [29].

By using oedomer cells or column of filled with compacted porous materials in which water is passing through as experimental percolation setup, the conductivity of only organophilic clays (organoclays with long alkyl chain surfactants) for water can be determined $[6,9]$. Their hydraulic conductivity is considerably increase of about two order of magnitude to those of the untreated clays. However, at our knowledge, no study deals with the characterization of the hydraulic behavior of short or moderate chain organoclays (adsorptive clays), nor tackle the importance of parameters about the chemical nature, length of the alkyl chains, density, arrangement of the surfactants or carbon content of organoclays in the conductivity for water. Thus, one of the objectives of this study aims at giving an overview by a fine characterization of the hydraulic behavior of a set of different organoclays for different density and arrangement of the surfactants (mono or bi-layer(s)) as well as organic contents. These organoclays were prepared with a referenced montmorillonite modified by alkyl 
quaternary ammonium surfactants having alkyl chains spreading out from 2 to 16 carbons and with or without benzyl groups.

Pharmaceuticals are frequently found in various water compartments and soils. While present at low concentration (range of $0.6-2 \mu \mathrm{g} \mathrm{L}^{-1}$ ), they were recognized to lead to harmful effects to several ecosystems. Among the pharmaceuticals, Amoxicillin (AMX), an antibiotic frequently is massively used due to its versality to treat a large spectrum of bacteria. Since, AMX is found in various water media underlining its persistence, this pharmaceutical was classified in the watch list of the European community about contaminants to be monitored. Based on well-known mass balance batch type experiments with synthetic solutions, previous works pointed the use of long alkyl chain organoclays, prepared by the benzyldimethyltetradecyl ammonium (BDTA) for the proper removal of AMX [12, 18, 30]. However, the adsorption of the zwitterionic pharmaceutical mainly occurred through the electrostatic forces while the hydrophobicity of the long chain surfactants plays a minor role $[2,12,18,21]$. In presence of charged species: inorganic ions (electrolytes) or competing pharmaceuticals, electrostatic interaction was easily perturbed (screening for instance), leading to a decrease of the adsorbed amount onto BDTA-Mt. While reducing the extent of the adsorption for long-chain organoclays, untreated clay mineral, in experimental conditions close to those of the natural environment with the consideration of the effects of competition among pollutants as well as the presence electrolytes exhibited performances similar to those of organoclays [2, 12, 18]. If long chain organoclays are commonly used as reference adsorbents for pharmaceuticals, rare studies focus on the use of short-chain or moderate organoclays such as TMA-Mt for the removal of pharmaceuticals [25, 27]. Thus, the second goal of this work consists in a comparative study of the adsorption capacities of the short and long chain organoclays (TMA-Mt and HDTMA-Mt respectively) representative of the 
hydromechanical properties of the organoclays in this study for the removal of amoxicillin (AMX) in kinetics and equilibrium batch adsorption experiments.

While organoclays were suggested as realistic and perennial alternatives in water remediation strategies, the majority of the studies were carried on at the equilibrium for batch adsorption experiments. However, realistic adsorption applications lean against dynamic percolation experiments with the use of materials as filters. Those experiments consist to a fine balance between the affinity (determined in batch equilibrium experiments) versus the retention time of a pollutant with a porous media. Then, the third objective of this study concerns the determination of the retention performances, in a percolation situation, of short and long chain organoclays, for a pharmaceutical: the amoxicillin (AMX), of two selected organoclays (TMA-Mt and HDTMA-Mt) representative of the hydromechanical properties of the organoclays studied in this work.

\section{MATERIALS AND METHODS}

\subsection{Materials}

The starting clay mineral was the Wyoming montmorillonite (Mt), supplied by the Source Clays Repository of the Clay Minerals Society. After $<2 \mu \mathrm{m}$ fractionation by gravity sedimentation, this Mt sample was $\mathrm{Na}^{+}$-exchanged by a well-established procedure $[1,3,19]$. This Na-Mt clay of which chemical formula is $\mathrm{Na}_{0.68}\left(\mathrm{Al}_{3.06} \mathrm{Fe}^{\mathrm{III}}{ }_{0.42} \mathrm{Mg}_{0.58}\right)\left(\mathrm{Si}_{7.90} \mathrm{Al}_{0.10}\right) \mathrm{O}_{20}(\mathrm{OH})_{4}$, shows a cation exchange capacity (CEC) of about $85.0 \pm 2.7 \mathrm{meq} / 100 \mathrm{~g}$ of calcined clay. Benzyl trimethyl ammonium (BTA), tetramethyl ammonium (TMA), butyl trimethyl ammonium (BTMA), trimethyl octyl ammonium (TOMA) and hexadecyl trimethyl ammonium (HDTMA) cationic surfactants were purchased from Sigma Adrich. The preparation of the organoclays was achieved by mixing at $250 \mathrm{rpm}$ for $24 \mathrm{~h}$ aqueous solutions of each surfactant at 40 and $100 \%$ of the CEC with Na-Mt. The 
resulting organoclays $\left(\mathrm{TMA}_{0.4}-\mathrm{Mt}\right.$, TMA-Mt, BTA $0.4-\mathrm{Mt}$, BTA-Mt, HDTMA ${ }_{0.4}-\mathrm{Mt}, \mathrm{BTMA}-$ Mt, TOMA-Mt, and HDTMA-Mt) collected in solid form after a centrifugation step were rinsed with water, dried at $90{ }^{\circ} \mathrm{C}$ for $48 \mathrm{~h}$ and then crushed in an agate mortar. Amoxicillin (6( $p$-hydroxy- $\alpha$-aminophenylacetamido) penicillanic acid, hereafter noted AMX), was purchased from Sigma-Aldrich Chemical and assumed to have a purity $>98 \%$.

\subsection{Experimental techniques}

X-ray diffraction (XRD) patterns were recorded in a conventional $\theta-\theta$ Bragg-Brentano configuration by using a Thermo Electron ARL'XTRA diffractometer equipped with a $\mathrm{Cu}$ anode $\left(\mathrm{CuK}_{\alpha}=1.5418 \AA\right)$ coupled with a $\mathrm{Si}(\mathrm{Li})$ solid detector. Experimental measurement parameters were $10 \mathrm{~s}$ counting time per $0.05^{\circ} 2 \theta$ step. Fourier transform infrared (FT-IR) measurements in the range 4000-650 $\mathrm{cm}^{-1}$ were recorded using a Thermo Nicolet 6700 FT spectrometer equipped with a deuterated triglycine sulfate (DTGS) detector and a Nicolet Continuum microscope. The powder samples were spread over a $\mathrm{NaCl}$ window of the microscope. The analyzed sample area was a square of side $100 \mu \mathrm{m}$ chosen under the microscope 15X Infinity Reflechromat objective. The analyses were performed in transmission mode and each spectrum corresponded to the average of 256 scans collected at $2.0 \mathrm{~cm}^{-1}$ resolution. The AMX concentrations before and after being in contact with organoclays and Na-Mt were obtained by UV-visible analysis using an Evolution 220 spectrophotometer (Thermo Scientific) at $226 \mathrm{~nm}$ (maximum of absorption).

Percolation experiments were performed using oedometer cells equipped with a separated injection system characterized by a controlled mechanical pressure of which equipment scheme and further details are published elsewhere. The oedometer cell was characterized by a $10 \mathrm{~mm}$ diameter, which requires low sample masses (ca. $300 \mathrm{mg}$ ), and so adapted for synthetic samples $[3,7]$. For each experiment, the sorbent materials were firstly compacted up to $0.5 \mathrm{MPa}$, that mimic geotechnical barriers experimental conditions, then totally unloaded. 
A mechanical stress of $0.3 \mathrm{MPa}$ was then applied at the lower boundary, while deionized water or amoxicillin solution at a concentration of $800 \mathrm{mg} \mathrm{L}^{-1}$, which was quite high comparatively to real contamination in a nature but facilitated us an experiment about a change of concentration of a AMX solution. That solution was injected by a syringe into the compacted sorbent material under the same constant pressure of $0.3 \mathrm{MPa}$, applied at the upper boundary. The sample thickness and the injected volume were monitored during percolation experiments. The leachates expelled from the porous media were regularly collected and weighted.

\subsection{Batch experiments}

AMX was used in batch adsorption experiments onto raw clay mineral and two selected organoclays: TMA-Mt and HDTMA-Mt using at least ten initial aqueous AMX solutions ranging from $10.0 \mathrm{mg} \mathrm{L}^{-1}$ to $4.0 \mathrm{~g} \mathrm{~L}^{-1}$. AMX of which molar mass is $365.4 \mathrm{~g} \mathrm{~mol}^{-1}$, shows a solubility of $9.58 \mathrm{~g} \mathrm{~L}^{-1}$, displays a $\log \mathrm{P}$ of 0.87 , and have two $p K_{a}$ values of 3.23 and 7.43 , respectively. The solid-to-liquid ratio was kept constant at $2.0 \mathrm{~g} \mathrm{~L}^{-1}$, where $100 \mathrm{mg}$ of sorbents were used for $50 \mathrm{~mL}$ of AMX aqueous solutions in centrifuge tubes. Samples were shaken on a rotary shaker at $250 \mathrm{rpm}$ during $24 \mathrm{~h}$ to reach the equilibrium then centrifuged at $5,500 \mathrm{rpm}$ for $25 \mathrm{~min}$. The $\mathrm{pH}$ of the medium was of 6.4 for which AMX is in a zwitterionic form (SI Figures 1-2). The entire resulting sorbents were dried at $100{ }^{\circ} \mathrm{C}$ for $48 \mathrm{~h}$ prior XRD and FTIR characterizations, whereas supernatants were removed and analyzed through UVvisible spectroscopy. The amount of adsorbed AMX was calculated by the difference between the initial and final concentrations after being into contact with the sorbents allowing one to represent the kinetics and equilibrium adsorption isotherms. 


\section{RESULTS AND DISCUSSION}

\subsection{Organization of the organoclays}

In this study, several organoclays were prepared with short, moderate and long alkyl chains surfactants of different nature (with different organic moieties) and at different loadings corresponding at $40 \%$ and $100 \%$ of the CEC. For mono-alkyl chain surfactants such as the series we investigated here, the length of the alkyl chain controls the expansion of the interlayer space $[26,28]$. Below a number of carbons of 8 (case of TMA, BTA, BTMA and TOMA), the intercalation of the surfactants leads to organoclays with a limitation of the interlayer space at 1.4-1.5 nm even with initial amount of surfactant larger than 1 CEC. Such enlargement of the interlayer space, that can be probed by X-ray diffraction, results from the incorporation of a monolayer arrangement of the surfactants that can be confirmed by infrared spectroscopy which gives additional information about the possible conformation changes of the organic species (see appendix data: SI Figures 3-6). FT-IR spectra confirmed this surfactant organization and show typical features characteristics of the organic compounds, such as the absorption bands at about $1450 \mathrm{~cm}^{-1}$ and $2920-2840 \mathrm{~cm}^{-1}$ related to the deformation and stretching vibrations of the $\mathrm{C}-\mathrm{H}$ of the organic moieties $\left(\mathrm{CH}_{3}\right.$ and $\mathrm{CH}_{2}$ of the alkyl chains) of the organic cations (SI Figures 3 and 6).

In contrast, HDTMA with a long alkyl chain of 16 carbons leads to the formation of different arrangements: lateral mono, bi-layer(s), and a paraffin structure [2, 14] (normal bilayer) within the interlayer space depending on the concentration of a surfactant. The proper intercalation of HDTMA was confirmed by XRD with a shift to low $2 \theta$ angular values of the $00 l$ reflection of the HDTMA ${ }_{0.4}-\mathrm{Mt}$ and HDTMA-Mt in contrast to the dehydrated NaMt which showed an interlayer space of $9.7 \AA$ (SI Figures 3-6). The expansion of the

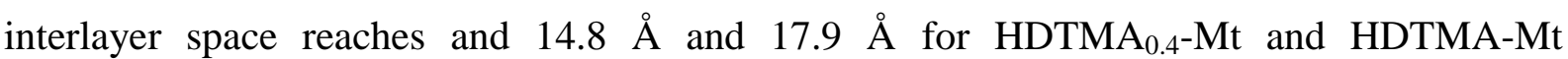


respectively. These values correspond to, with the knowledge of the molecular size of HDTMA to mono and bi-lateral bilayers organization (Figure 1).

The surfactant arrangements can be drawn and summarized as follows in Figure 1: a lateral monolayer $\left(\mathrm{TMA}_{0.4}-\mathrm{Mt}\right.$, TMA-Mt, BTA ${ }_{0.4}-\mathrm{Mt}$, BTA-Mt, BTMA-Mt, TMOA-Mt and HDTMA $_{0.4}-\mathrm{Mt}$ ) and bilayers (HTDMA-Mt). This offered a large range of materials with different organic content and versatile and complementary properties. The organoclays, prepared at $40 \%$ of the CEC, can still exchange the inorganic $\mathrm{Na}^{+}$cations and thus show a dual hydrophilicity/hydrophobicity behavior. In contrast, HDMA-Mt exhibits an organophilic character (e. g. organophilic clay) and even an anion adsorption ability, with outstanding adsorption properties for a wide range of organic products as recent works emphasized [2, 12$14,20]$.

\subsection{Hydraulic properties of the organoclays}

The hydraulic conductivity characterization of the organoclays represents one of the most important parameter to consider if one thinks about the potential applications of these hybrid materials as geotechnical barriers or adsorbents and their ability to retain contaminants in a dynamic way [1, 3, 6-9].

The measured axial displacements of the piston along the experiments allowed us to calculate the axial swelling strain $\left(\varepsilon_{l}\right)$ which corresponds to the osmotic swelling of the layered materials (SI Figures 7-8 related to the experimental set-up of the oedometer cells). Na-Mt displayed a mechanical permanent regime (i.e., when an asymptotic value of $\varepsilon_{l}$ was reached) after 10 days of percolation, together with a high osmotic swelling at equilibrium of 37\%. In contrast, the whole organoclays revealed a spontaneous mechanical permanent regime and a non-significant osmotic swelling (0-5\%) even those prepared at a loading of $40 \%$ of the CEC. A similar low osmotic swelling was previously observed for a $\mathrm{NH}_{4}{ }^{+}-\mathrm{Mt}$ 
showing a value one order of magnitude lower than Na-Mt, underlining the importance of the nature of the cations located within the interlayer space.

The resulting data obtained by the oedometry experiments consist in the representation of the volume of the leachate along the time (Figure 2). If the length of the alkyl chains and their density represent important parameters in the case of the adsorption of organic contaminants, the hydromechanical properties appear to not be related to organization of the surfactants, nor the length of the alkyl chains. The short chain organoclays $\left(\mathrm{TMA}_{0.4}-\mathrm{Mt}, \mathrm{TMA}-\mathrm{Mt}\right)$ with low content of carbon (below 3\%) show a certain permeability with the obtention of the permanent regime after 3 hours, while it requires several days and even weeks for Na-Mt. Similarly, it took less than 3 hours to get the end of transient regime for $\mathrm{BTA}_{0.4}-\mathrm{Mt}$ that still contains a low content of carbon (close to 2.5\%). At such organic contents (below 3\%), the adsorption of the short alkyl surfactants is not sufficient to cover the whole surface of the clay mineral $[27,29]$. As a result, the zeta potential of such organoclays does not differ much from a clay mineral by exhibiting a negative charge while showing a hydrophobic character [31]. In contrast, for the other organoclays: HDTMA ${ }_{0.4}-\mathrm{Mt}$ and HTDMA-Mt and even the adsorptive clays: BTA-Mt, BTMA-Mt, TMOA-Mt, water instantly streamed out from the oedometer cell underlining the poor impermeability of those hybrid materials. Even for short and moderate chain organoclays (BTA-MT, BTMA-Mt, TMOA-Mt), showing a monolayer arrangement, their hydromechanical behavior is completely different from those of Na-Mt, or TMA-Mt. However, with organic contents larger than $5 \%$, the quantities of surfactant are enough to ensure a global covering of the clay mineral surface without the possibility to get a bilateral organization, leading to the formation of continuous organic phase. Such coverage contributes to a drastic change in both the hydrophobicity as well as the electric behavior or zeta potential of the organoclays [31]. 
A permanent regime of the hydro-mechanical can be defined by the volume of leachate and the strain equilibrium allowing the calculation of a hydraulic conductivity, $K_{e q}$, through the Darcy's law (1):

$$
K_{e q}=\frac{Q}{i S}
$$

where $Q$ is the measured volumetric streaming $\left(\mathrm{m}^{3} \mathrm{~s}^{-1}\right)$ at the steady state, $i$ the hydraulic gradient (unit?), and $S$ is the cross-sectional area of the oedometer cell (here, $7.85410^{-5} \mathrm{~m}^{2}$ ). A hydraulic constant $\left(K_{i}\right)$ in the transient regime can similarly be calculated. When organic cations replace the exchangeable inorganic cations, both $K_{i}$ and $K_{e q}$ of the organoclays for water are at least one order of magnitude larger than Na-Mt and their behavior mainly depends on the carbon content of the hybrid layered materials (SI Table 1 and Figure 5) much more than the nature of the surfactant (organic moieties: alkyl chains or benzyl group) or its loading and the presence of accessible inorganic $\left(\mathrm{Na}^{+}\right)$cations. Indeed, for TMA organoclays (i.e., $\mathrm{TMA}_{0.4}-\mathrm{Mt}$ and TMA-Mt), the behavior of the injected volume appears the same besides the presence of $\mathrm{Na}^{+}$cations for $\mathrm{TMA}_{0.4}-\mathrm{Mt}$. For a carbon content higher than $2.5 \%$ wt. (case of $\mathrm{BTA}_{0.4}-\mathrm{Mt}$ ), no equilibrium regime could be achieved. BDTA-Mt displayed a similar behavior as $\mathrm{HDMA}_{0.4}-\mathrm{Mt}$ and the other organoclays (BTMA-Mt, TMOA-Mt and HDTMAMt) with a similar value for $K_{i}$ about $5.0 \times 10^{-9}-6.5 \times 10^{-9} \mathrm{~m} \mathrm{~s}^{-1}$ (Figure 3).

These values are in agreement with previous studies, conducted on organoclays prepared with cetyl trimethyl ammonium and quaternized ethoxylated fatty amine, using a rigid-wall compaction mold permeameter [6]. In addition, the hydro behavior of the studied organoclays also appears similar to that one of a commercial bentonite modified by HDTMA showing a drastic increase of its permeability [8]. Due to their hydrophobic behavior, organoclays revealed a lower cohesion shown by unconfined compression strength tests, together with a lower swelling pressure and a decrease of their consistency limits (i.e., liquid and plastic limits) $[6,9,32]$. 
Besides some organoclays still keep some inorganic cations at a large content ( $60 \%$ of the CEC), it appeared that their swelling behavior likely depends on the external surface of the layers and particles (which should be covered by the organic cations) leading to a lack of cohesion between particles. The presence of cationic surfactants even at low loadings deeply modify the transport of water molecules within the interlayer space and thus reduce the macroscopic swelling and hydraulic behavior of the layered materials. Thus, the hydrophobic character of the investigated cationic organoclays considerably affects a hydraulic behavior that differs from an untreated Na-Mt, leading to an increase of the permeability of the layered materials with a fast water streaming for the most hydrophobic ones that obviously represent a critical issue in possible use of these materials in water remediation or for environmental application purposes.

\subsection{Adsorption isotherms study of the amoxicillin with organoclays}

Depending on their organic content, the hydromechanical properties of organoclays can be classified in two main groups: $\mathrm{TMA}_{0.4}-\mathrm{Mt}$, TMA-Mt, BTA $0.4-\mathrm{Mt} v s$ BTA-Mt, BTMA-Mt, TOMA-Mt, HDTMA ${ }_{0.4}-\mathrm{Mt}$ and HTDMA-Mt. Thus, we decided to perform both the kinetic and equilibrium batch adsorption experiments of AMX onto TMA-Mt and HDTMA-Mt respectively representative of the hydromechanical properties of the organoclays in this study.

Recent batch experiment studies about the adsorption of AMX in its zwitterionic form onto modified clay mineral by surfactants revealed the outstanding adsorption properties of organoclays. This current study again confirms the great affinity of AMX for organoclays with however a linear growth of the adsorbed amount, as the equilibrium concentration is increased without the observation of any steady state or plateau underlining the absence of any saturation. 
In addition, the adsorption in batch experiment conditions drove to large amount of AMX onto the organoclays: from $6.0 \times 10^{-4}$ to $1.4 \times 10^{-3} \mathrm{~mol} \mathrm{~g}^{-1}$, respectively, for TMA-Mt and HDTMA-Mt that contrasted to Na-Mt with only reaching $2.4 \times 10^{-4} \mathrm{~mol} \mathrm{~g}^{-1}$, values coherent to previous observations with organoclays and a raw Indonesian bentonite [33] (Figure 4). However, the adsorption isotherms at the equilibrium here do not follow a traditional Langmuir ' $L$ ' shape isotherm since no saturation, nor steady state for the adsorption onto the porous materials could be observed and therefore we used a Freundlich model to fit the data.

The empirical Freundlich equation models the adsorption of analytes on heterogeneous surfaces (such as clay minerals and organoclays may show) in a liquid state. In contrast to a Langmuir model, based on the assumption of a monolayer adsorption on a structurally homogeneous adsorbent, with all the sorption sites are identical and energy equivalent, the Freundlich model is not restricted to the organization of only one monolayer. The Freundlich model is expressed as follows (2):

$$
q_{e}=K_{F} C_{e}^{1 / n}
$$

where $q e$ is the equilibrium AMX amount adsorbed on sorbents ( $\left.\mathrm{mol} \mathrm{g}^{-1}\right), C_{e}$ the equilibrium AMX concentration in the resulting solution $\left(\mathrm{mol} \mathrm{L}^{-1}\right), K_{F}$ the Freundlich affinity constant $(\mathrm{L}$ $\left.\mathrm{g}^{-1}\right)$ that quantifies the extent of adsorption, and $n$ a constant indicating the degree of nonlinearity between AMX and the sorbents.

By using $K_{F}$ (SI Table 2), the affinity of AMX is as follows: HDTMA-Mt > TMA-Mt > Na-Mt. The slight excess of the organic TMA and HDTMA cations combined with their hydrophobic character contribute to the adsorption of AMX with its carboxylate $\left(-\mathrm{COO}^{-}\right)$ moieties through electrostatic and hydrophobic interactions. Moreover, the Freundlich coefficients $n$ of non-linearity are above 1.0 reveal that the sorption of AMX is favorable onto 
both organoclays. In contrast, the adsorption data of AMX onto Na-Mt could be almost fitted by a polynomial of the first order since $n$ is very close to 1.0 in the range of the studied equilibrium concentrations. This indicates that the ratio between the equilibrium AMX concentration and the amount adsorbed on Na-Mt, also labelled as the distribution coefficient $\left(K_{d}\right)$ or partition coefficent, remains constant and describes a cation exchange with $\mathrm{Na}^{+}$, leading to its intercalation with an increase of the interlayer spacing to nearly $15 \AA$ in agreement with a molecular size of AMX (SI Figure 1) [34].

The improvement of the adsorption properties of organoclays compared to the $\mathrm{Na}^{+}-$ exchanged Mt was previously observed for AMX and other pharmaceuticals $[12,18]$. Their hydrophobic character and the wide opening of their interlayer space as well as the presence of possible positive charge resulting from the excess of adsobed HDTMA are as numerous parameters to explain the adsorption efficiency of organoclays [2, 12-14, 18]. However, while infrared spectrocopy allowed us to appreciate the proper adsorption on the whole adsorbents, no enlargements of the interlayer space of both HDTMA-Mt or TMA-Mt could be observed by X-ray diffraction (data not shown). Although, no structural changes could be observed for the organoclays after being in contact with AMX, a possible intercalation of a pharmaceutical nevertheless cannot be excluded in the light of the adsorbed amount as well as the small molecular size of AMX. In other words, the prior enlargements of the interlayer space due to the presence of surfactants may hide the possible intercalation of AMX. Further experiments, such extraction of the chemicals by organic solvents or pyrolysis coupled with mass spectroscopy may be done in a next future to precisely find out the location of AMX onto both TMA-Mt and HDTMA-Mt.

Organoclays prepared with long alky chains such HDTMA for instance generate a organic media or pationning media that considerably favor or enhance the adsorption of organic compounds, and especialy hydrophobic species [27, 29]. At a loading of 1 CEC, 
HDTMA-Mt shows a large hydrophobic character with the inclusion of hydrophobic organic phase covering the whole clay mineral surface leading to an electric charge close to 0 and even a positive one (if one considers a slight excess of surfactants) [31]. Thus, with these properties, HDTMA-Mt proves to be the most efficient adsorbent in batch equibrium experimental conditions for the removal of AMX. In contrast, TMA-Mt is defined as an adsorptive clay without the generation of any continuous organic layer on its surface [25, 27]. Despite a preparation at a low organic content, the presence of TMA cations within the interlayer space contributes to keep the layers away allowing a possible confinement of further organic species or adsorption onto the external treated surface. In addition, as a chemical modifier of surface, the TMA switches the hydrophilic nature of the clay mineral surface to hydrophobic while slightly changing its electric charge [31]. As previous works emphasized for the adsorption of organic compounds on TMA-Mt [25, 27], the slight modification of a clay mineral surface by TMA favors the adsorption of hydrophobic compounds, as it could be the case for AMX. However HDTMA-Mt as being the most hydrophobic material in this study is revealed to be the best efficient adsorbent for the removal of AMX.

Various previous batch adsorption studies pointed out the interests to use activated carbons of different size fractions (controlling the surface areas of these porous materials) for the removal of AMX of which adsorption spreaded out from $8.6 \times 10^{-6}$ to $5.2 \times 10^{-4} \mathrm{~mol} \mathrm{~g}^{-1}$ $[33,35]$. Thus, the sorption capacity of the HDTMA-Mt organoclay appears to be more efficient than activated carbons and clay minerals. However, the adsorption properties of cationic organoclays have to been put in perspective and requires to take into perspetive their interests in the presence of electrolytes or in complex solutions, where competive effects occur between organic molecules, where their efficiency to the removal of pharmaceuticals appears similar (and even lower) to raw Na-Mt. 
The prediction of the removal rate of AMX with the use of organoclay represents one of the most important issue for an effective system design based on these layered materials which show some promising adsorption properties in batch experiment conditions at the equilibrium. The sorption processes as well as its rate could be determined through kinetics adsorption experiments with a solution of AMX at an initial concentration of $100 \mathrm{mg} \mathrm{L}^{-1}$, which were performed for TMA-Mt and HDTMA-Mt and Na-Mt (Figure 5).

The evolution of the adsorbed amounts over time for the three adsorbents appears substantially identical. Indeed, the curves show two distinct types of regimes. At the beginning, a total adsorption occurs due to the large quantity and availability of adsorption sites. Then, after a time of about $50 \mathrm{~min}$, the adsorbed amounts tend to be constants and reach $1.2 \times 10^{-4} \mathrm{~mol} \mathrm{~g}^{-1}$ and $2.2 \times 10^{-4} \mathrm{~mol} \mathrm{~g}^{-1}$, respectively, for TMA-Mt and HDTMA-Mt in contrast to Na-Mt $\left(1.1 \times 10^{-4} \mathrm{~mol} \mathrm{~g}^{-1}\right)$, underlining an equilibrium between the $\mathrm{AMX}$ concentration remaining in solution and the amount adsorbed onto the layered materials. The organoclay HDTMA-Mt seems to show a better affinity with AMX and corroborates the previous adsorption data at the equilibrium.

To better understand the adsorption mechanisms and kinetics, the data were analyzed using both pseudo-first and pseudo-second order kinetic equations that model a rate of direct adsorption/desorption process (that can be understood as a kind of chemical reaction) determining the overall sorption kinetics. The pseudo first-order rate equation is expressed as (3):

$$
q_{t}=q_{e} \cdot\left(1-e^{-k_{1} \cdot t}\right)
$$

The pseudo second-order rate equation was used in its linear form (4) [11]: 


$$
\frac{t}{q_{t}}=\frac{1}{k_{2} q_{e}^{2}}+\frac{t}{q_{e}}
$$

where $q_{t}$ is the amount (mol $\mathrm{g}^{-1}$ ) of AMX adsorbed at time $t$ (min), $q_{e}$ is the pseudoequilibrium AMX sorbed amount $\left(\mathrm{mol} \mathrm{g}^{-1}\right)$, and $k_{1}\left(\mathrm{~s}^{-1}\right)$ and $k_{2}\left(\mathrm{~g} \mathrm{~mol}^{-1} \mathrm{~s}^{-1}\right)$ are the first and second-order sorption rate constants, respectively.

Based on the correlation coefficients that spread out from 0.9744 to 0.9986 , except that of Na-Mt, it appears that the pseudo-second order model better fitted the data (SI Table 3). Nevertheless, the data deduced by the fitting using both models and the $k_{1}$ and $k_{2}$ constants provide similar information related to a time scaling factor required to reach an equilibrium state by the system. With the inverse of the $k_{l}$ constants bearing the physical meaning as a time to reach an equilibrium, the transfer of AMX seems to be faster for HDTMA-Mt (about $10 \mathrm{~min}$ ) followed by Na-Mt (25 min) and TMA-Mt (40 min). Similarly, $k_{2}$ constants and their large values obtained confirm the same trend about the relative fast adsorption of AMX onto the whole adsorbents with however a quicker process onto the HDTMA-Mt. Here again, the presence of the surfactants and an organic media combined with a large opening of the interlayer space facilitate the adsorption of AMX.

\subsection{Percolation of a solution of amoxicillin through organoclays}

Batch kinetics and equilibrium adsorption experiments demonstrated the affinity of AMX to the whole adsorbents (organoclays and $\mathrm{Na}-\mathrm{Mt}$ ), that was quickly adsorbed (at a time below $40 \mathrm{~min}$ ). Under the experimental conditions tested (in the absence of electrolytes and without the presence of other organic molecules or other colloidal phases), organoclays prepared with long carbon chain surfactants prove to be the most effective materials for the removal of the antibiotic. 
In the light of these promising results, it was relevant to simulate the adsorption of AMX through percolation conditions. The hydro-plastic behavior of organoclays remains dependent on the amount of carbon, where the surfactants screen up the cohesion forces between particles. This promotes preferential paths for the passage of water which quickly takes place through the porous materials with the collection of leachates after only few minutes (below 10 $\min )$.

Thus, a question arose about the behavior of hybrid materials in light to the short contact time (in the same order of magnitude than those of the kinetics study) between the pollutant and the porous materials in percolation experiments. A solution of AMX at an initial concentration of $800 \mathrm{mg} \mathrm{L}^{-1}(2.2 \mathrm{mM})$ was percolated through the whole adsorbents: Na-Mt, TMA-Mt and HDTMA-Mt and the leachates were collected for different times, when it was possible (for Na-Mt, no leachates could be obtained in the experimental time window).

As expected, the hydraulic conductivities of organoclays remain identical at about $8.7 \times$ $10^{-10} \mathrm{~m} \mathrm{~s}^{-1}$ and $6.2 \times 10^{-9} \mathrm{~m} \mathrm{~s}^{-1}$ for TMA-Mt $\left(6.6 \times 10^{-10} \mathrm{~m} \mathrm{~s}^{-1}\right.$ with only water $)$ and HDTMAMt $\left(6.7 \times 10^{-9} \mathrm{~m} \mathrm{~s}^{-1}\right)$, respectively. The concentration of the antibiotic after the passage through the adsorbents was measured (by UV spectroscopy) and is shown as a function of time in Figure 6. After a quick passage through the organoclays, the concentration of AMX was considerably reduced for HDTMA-Mt with a decrease of about $80 \%$ but increased with time (underlining the poor retention ability of HDTMA-Mt) while it was slightly decreased (only 5-10\%) for adsorptive TMA-Mt organoclay. FT-IR spectroscopy measurements of both TMA and HDTMA organoclays, after being in contact with at the end of the percolation experiments, confirmed the proper adsorption of AMX with additional bands related to the antibiotic on those of the organoclays (Figure 7).

Nevertheless, this final percolation experiment of an antibiotic emphasized the limits of the studied organoclays for environmental applications. Indeed, with a short contact time 
between the layered materials and the organic contaminant, the concentration of AMX in the leachates was still significant and thus inappropriate in water remediation strategies, nor for the protection of the environment. This points out to differently design the preparation of the hybrid materials (with nonionic surfactants for instance) or to combine cationic organoclays with other porous materials. Although showing promising results in batch method which are quite useful preliminarily experiments, the conclusions deduced cannot dictate nor predict the behavior of the organoclays within porous media system. Thus, it implies to be cautious about the design of environmental systems based on organoclays and may orientate further works to use nonionic organoclays or mixture of both organoclays and clay minerals.

\section{CONCLUSIONS}

In this study, the hydraulic conductivity of a set of short and moderate chain organoclays (TMA-Mt, BTA-Mt, BTMA-MT and TOMA-Mt), and a long chain organoclay (HDTMAMt) was determined through percolation experiments by using an oedometric cell coupled with an injection system under controlled pressure. The presence of surfactants even at low content screen up the cohesion forces between particles, leading to an increase of the hydraulic conductivity which were about 100 times larger than that-one of Na-Mt.

Then, the performances of TMA-Mt (representative organoclay at low organic content) and HDMA-Mt (organoclay at a carbon content $>5 \%$ ) organoclays for the retention of a pharmaceutical: the amoxicillin (AMX) were investigated. Besides showing outstanding adsorption properties for AMX in batch adsorption conditions, the retention time in percolation situation was not sufficient to ensure a proper removal of the pharmaceutical with the use of the organoclays.

Thus, the interests of organoclays obviously needs to be taken into perspective in a context of porous media or in any environmental applications and requires a careful design of 
the systems for the last purposes. Last but not the least, while being the adsorbent with the poorest affinity to AMX (within the experimental conditions investigated in this study), raw Mt, with its outstanding hydro-mechanical properties and osmotic swelling which is of first concern finally as this study pointed out, appears to be still the most interesting material as the use of a geotechnical barrier that can includes organoclays in low extent to improve the adsorption of organic contaminants.

\section{ACKNOWLEDGEMENTS}

The authors are grateful to Tiago De Oliveira and Rina Sato for their technical supports in this study.

\section{REFERENCES}

[1] M. Gautier, F. Muller, L. Le Forestier, J.M. Beny, R. Guegan, NH4-smectite: Characterization, hydration properties and hydro mechanical behaviour, Applied Clay Science 49 (2010) 247-254.

[2] R. Guégan, Organoclay applications and limits in the environment, Comptes Rendus Chimie 22 (2019) 132-141.

[3] L. Le Forestier, F. Muller, F. Villieras, M. Pelletier, Textural and hydration properties of a synthetic montmorillonite compared with a natural Na-exchanged clay analogue, Applied Clay Science 48 (2010) 18-25.

[4] T. Thiebault, M. Boussafir, R. Guégan, C. Le Milbeau, L. Le Forestier, Clayey-sand filter for the removal of pharmaceuticals from wastewater effluent: percolation experiments, Environmental Science: Water Research \& Technology 2 (2016) 529-538.

[5] T. Thiebault, M. Boussafir, L. Le Forestier, C. Le Milbeau, L. Monnin, R. Guégan, Competitive adsorption of a pool of pharmaceuticals onto a raw clay mineral, RSC Advances 6 (2016) 6525765265.

[6] S. Akbulut, Z.N. Kurt, S. Arasan, Y. Pekdemir, Geotechnical properties of some organoclays, Sadhana 38 (2013) 317-329.

[7] A. Jullien, C. Proust, L. Le Forestier, P. Baillif, Hydro-chemio-mechanical coupling effects on permeability and swelling behaviour of a Ca smectite soaked by Cu solutions, Applied Clay Science 21 (2002) 143-153.

[8] L.Y. Li, W.T. Denham, The Hydraulic Conductivity and Adsorptivity of Organoclay in a SandBentonite Barrier to Hydrophobic Organic Chemicals, Environmental Technology 21 (2000) 14291443.

[9] S. Akbulut, Z. Nese Kurt, S. Arasan, Surfactant modified clays consistency limits and contact angles, Earth Sciences Research Journal 16 (2012) 95-101.

[10] G. Akçay, E. Kılınç, M. Akçay, The equilibrium and kinetics studies of flurbiprofen adsorption onto tetrabutylammonium montmorillonite (TBAM), Colloids and Surfaces A: Physicochemical and Engineering Aspects 335 (2009) 189-193.

[11] P.-H. Chang, W.-T. Jiang, Z. Li, C.-Y. Kuo, J.-S. Jean, W.-R. Chen, G. Lv, Mechanism of amitriptyline adsorption on Ca-montmorillonite (SAz-2), Journal of Hazardous Materials 277 (2014) 44-52. 
[12] T. De Oliveira, E. Fernandez, L. Fougère, E. Destandau, M. Boussafir, M. Sohmiya, Y. Sugahara, R. Guégan, Competitive Association of Antibiotics with a Clay Mineral and Organoclay Derivatives as a Control of Their Lifetimes in the Environment, ACS Omega 3 (2018) 15332-15342.

[13] T. De Oliveira, R. Guégan, Coupled Organoclay/Micelle Action for the Adsorption of Diclofenac, Environmental Science \& Technology 50 (2016) 10209-10215.

[14] T. De Oliveira, R. Guégan, T. Thiebault, C.L. Milbeau, F. Muller, V. Teixeira, M. Giovanela, M. Boussafir, Adsorption of diclofenac onto organoclays: Effects of surfactant and environmental $(\mathrm{pH}$ and temperature) conditions, Journal of Hazardous Materials 323 (2017) 558-566.

[15] R. Guégan, Intercalation of a Nonionic Surfactant (C10E3) Bilayer into a Na-Montmorillonite Clay, Langmuir 26 (2010) 19175-19180.

[16] R. Guégan, Confinement effects on water structure in membrane lyotropic phases, Journal of Colloid and Interface Science 358 (2011) 485-490.

[17] R. Guegan, Self-assembly of a non-ionic surfactant onto a clay mineral for the preparation of hybrid layered materials, Soft Matter 9 (2013) 10913-10920.

[18] R. Guégan, T. De Oliveira, J. Le Gleuher, Y. Sugahara, Tuning down the environmental interests of organoclays for emerging pollutants: Pharmaceuticals in presence of electrolytes, Chemosphere 239 (2020) 124730.

[19] R. Guégan, M. Gautier, J.-M. Beny, F. Muller, ADSORPTION OF A C10E3 NON-IONIC SURFACTANT ON A Ca-SMECTITE, Clays and Clay Minerals 57 (2009) 502-509.

[20] R. Guégan, M. Giovanela, F. Warmont, M. Motelica-Heino, Nonionic organoclay: A 'Swiss Army knife' for the adsorption of organic micro-pollutants?, Journal of Colloid and Interface Science 437 (2015) 71-79.

[21] R. Guégan, E. Veron, L. Le Forestier, M. Ogawa, S. Cadars, Structure and Dynamics of Nonionic Surfactant Aggregates in Layered Materials, Langmuir 33 (2017) 9759-9771.

[22] X. Jin, S. Zha, S. Li, Z. Chen, Simultaneous removal of mixed contaminants by organoclays Amoxicillin and Cu(II) from aqueous solution, Applied Clay Science 102 (2014) 196-201.

[23] J. Madejová, L'. Sekeráková, V. Bizovská, M. Slaný, L'. Jankovič, Near-infrared spectroscopy as an effective tool for monitoring the conformation of alkylammonium surfactants in montmorillonite interlayers, Vibrational Spectroscopy 84 (2016) 44-52.

[24] M. Slaný, L'. Jankovič, J. Madejová, Structural characterization of organo-montmorillonites prepared from a series of primary alkylamines salts: Mid-IR and near-IR study, Applied Clay Science 176 (2019) 11-20.

[25] L. Groisman, C. Rav-Acha, Z. Gerstl, U. Mingelgrin, Sorption of organic compounds of varying hydrophobicities from water and industrial wastewater by long- and short-chain organoclays, Applied Clay Science 24 (2004) 159-166.

[26] H. He, Y. Ma, J. Zhu, P. Yuan, Y. Qing, Organoclays prepared from montmorillonites with different cation exchange capacity and surfactant configuration, Applied Clay Science 48 (2010) 67-72.

[27] S.Y. Lee, S.J. Kim, S.Y. Chung, C.H. Jeong, Sorption of hydrophobic organic compounds onto organoclays, Chemosphere 55 (2004) 781-785.

[28] M.A. Osman, M. Ploetze, P. Skrabal, Structure and Properties of Alkylammonium Monolayers Self-Assembled on Montmorillonite Platelets, The Journal of Physical Chemistry B 108 (2004) 25802588.

[29] Y. Park, G.A. Ayoko, R.L. Frost, Application of organoclays for the adsorption of recalcitrant organic molecules from aqueous media, Journal of Colloid and Interface Science 354 (2011) 292-305.

[30] T. De Oliveira, M. Boussafir, L. Fougère, E. Destandau, Y. Sugahara, R. Guégan, Use of a clay mineral and its nonionic and cationic organoclay derivatives for the removal of pharmaceuticals from rural wastewater effluents, Chemosphere 259 (2020) 127480.

[31] B. Bate, S.E. Burns, Effect of total organic carbon content and structure on the electrokinetic behavior of organoclay suspensions, Journal of Colloid and Interface Science 343 (2010) 58-64.

[32] B.H. Cipriano, S.R. Raghavan, P.M. McGuiggan, Surface tension and contact angle measurements of a hexadecyl imidazolium surfactant adsorbed on a clay surface, Colloids and Surfaces A: Physicochemical and Engineering Aspects 262 (2005) 8-13. 
[33] E.K. Putra, R. Pranowo, J. Sunarso, N. Indraswati, S. Ismadji, Performance of activated carbon and bentonite for adsorption of amoxicillin from wastewater: Mechanisms, isotherms and kinetics, Water Research 43 (2009) 2419-2430.

[34] G. Limousin, J.P. Gaudet, L. Charlet, S. Szenknect, V. Barthès, M. Krimissa, Sorption isotherms: A review on physical bases, modeling and measurement, Applied Geochemistry 22 (2007) 249-275.

[35] M.A.E. de Franco, C.B. de Carvalho, M.M. Bonetto, R.d.P. Soares, L.A. Féris, Removal of amoxicillin from water by adsorption onto activated carbon in batch process and fixed bed column: Kinetics, isotherms, experimental design and breakthrough curves modelling, Journal of Cleaner Production 161 (2017) 947-956. 


\section{FIGURES}

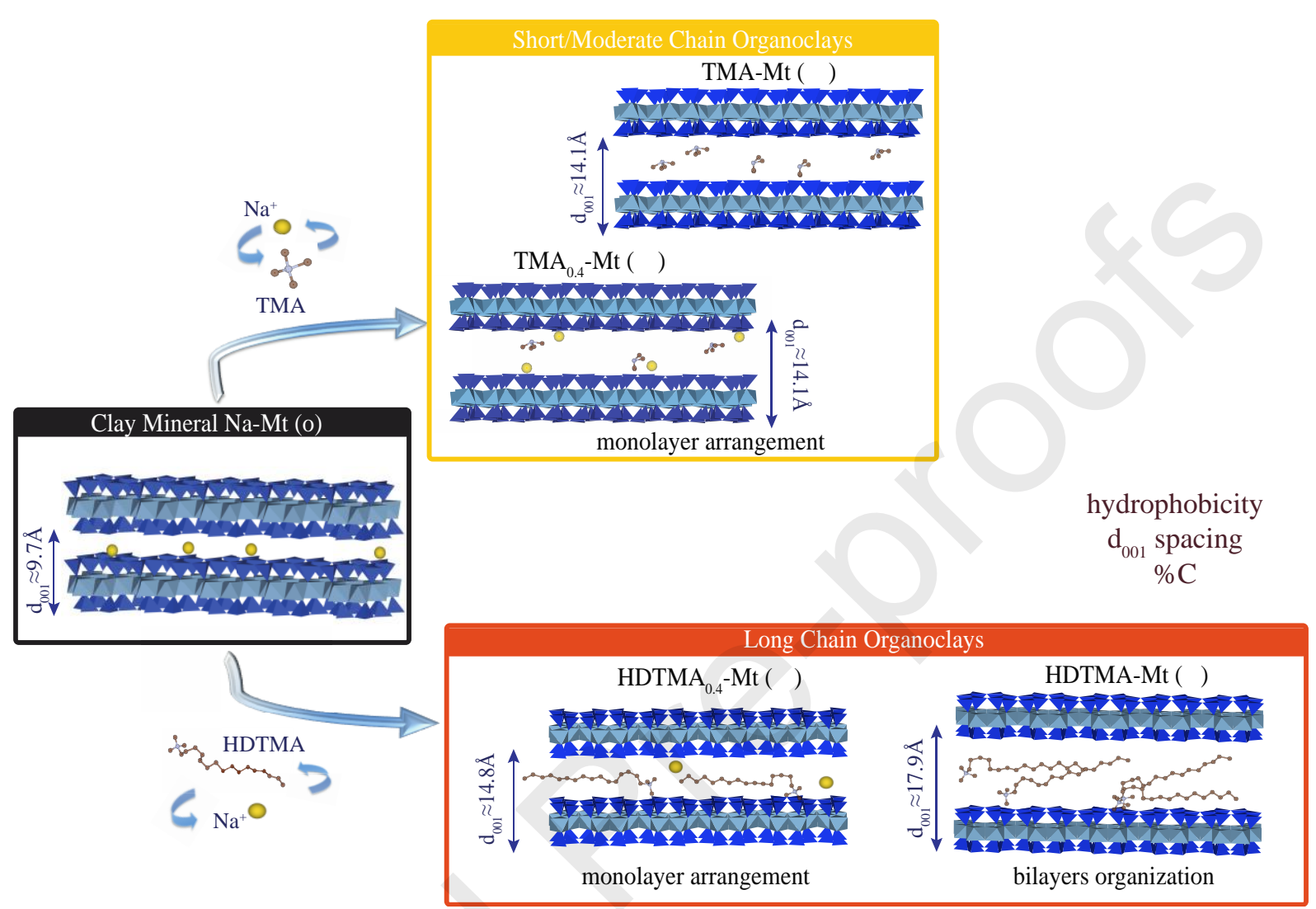

Fig. 1. Schematic representations of selected studied organoclays: TMA-Mt as representative organoclay for the short or moderate chain organoclays that can be prepared with the use of TMA, BTA, BTMA, TOMA and an organophilic clay made by long alkyl chain HDTMA surfactant. Short-moderate chain organoclays show a limited expansion of the interlayer space reaching a value of 1.4-1.5 $\mathrm{nm}$ even at high loadings (above $1 \mathrm{CEC}$ ). In contrast, HDTMA-Mt organoclays display a lateral monolayer arrangement for $\mathrm{HDTMA}_{0.4}-\mathrm{Mt}(60 \%$ of the compensating cations are preserved) to a lateral bilayer organization at 1CEC of surfactant (where $100 \%$ of inorganic cations were exchanged with organic cations). 


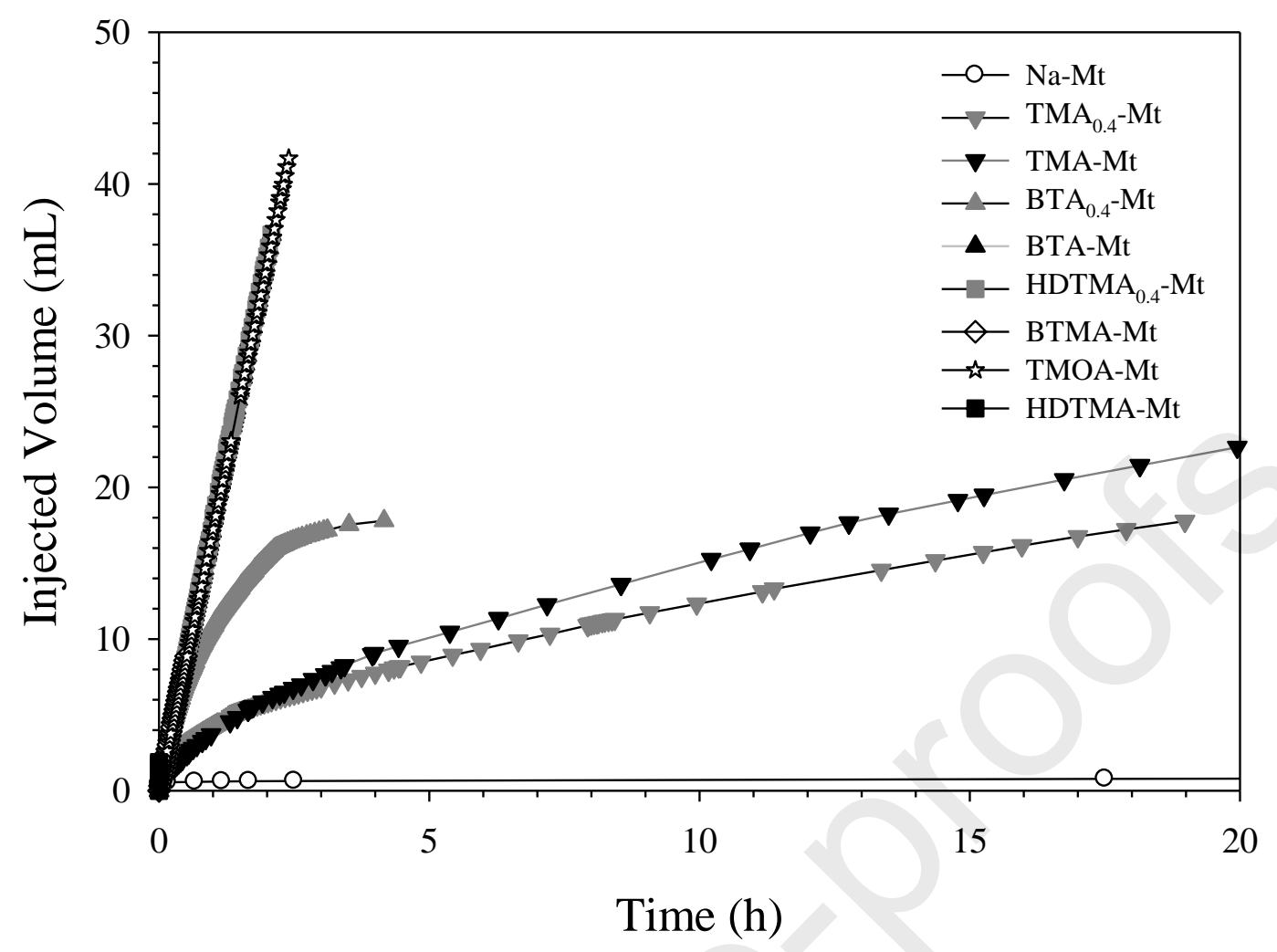

Fig. 2. Representation of the injected volume of water as a function of the time (in h) for the characterization of the hydric behavior of the whole organoclays as well as the raw clay mineral. 


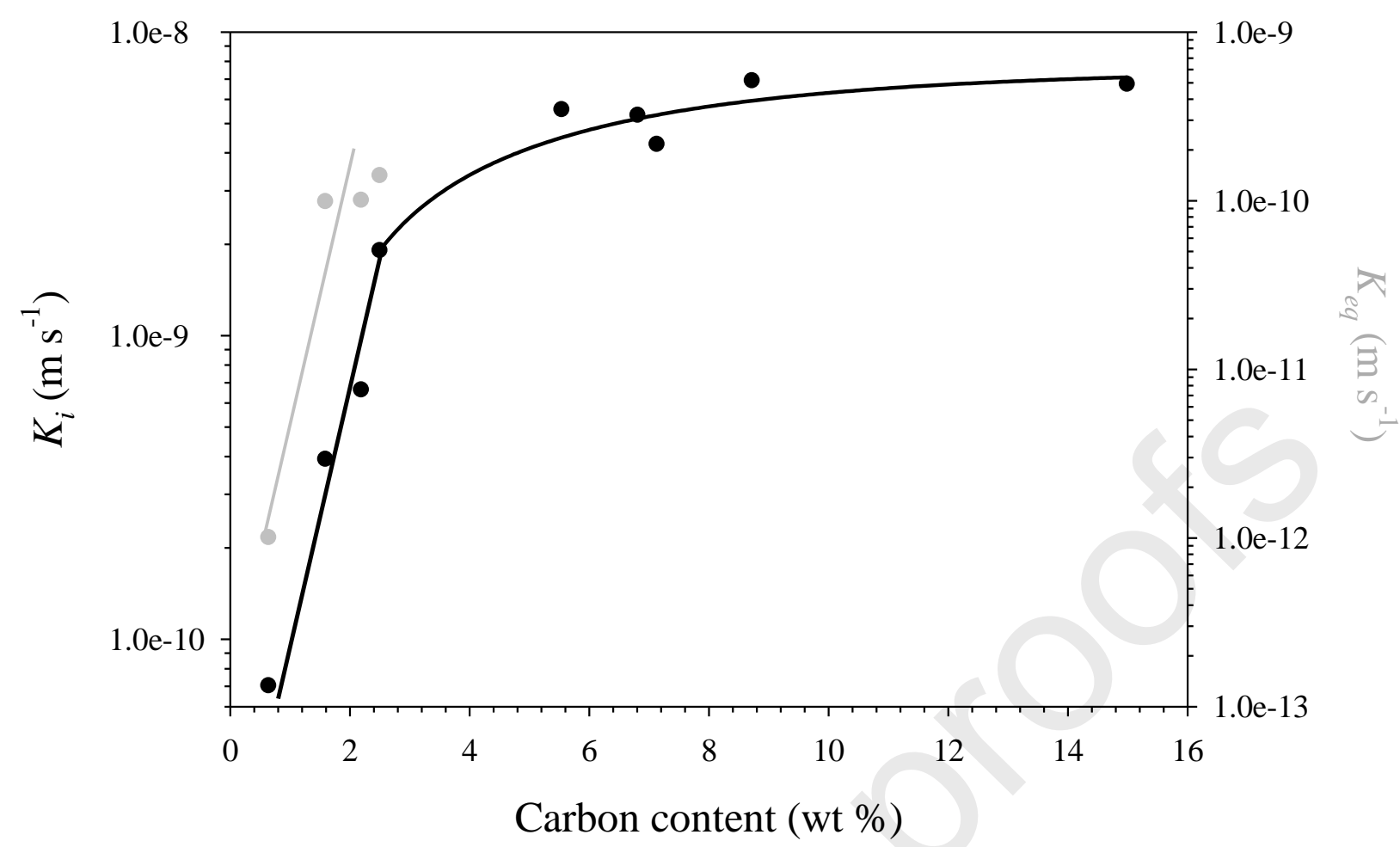

Fig. 3. Log scale representation of both the initial (black circle) and equilibrium (gray circle) hydraulic constants of the studied organoclays as a function of the content of carbon controlled by the loading of the cationic surfactants, which were intercalated through cation exchange in the layered materials. 


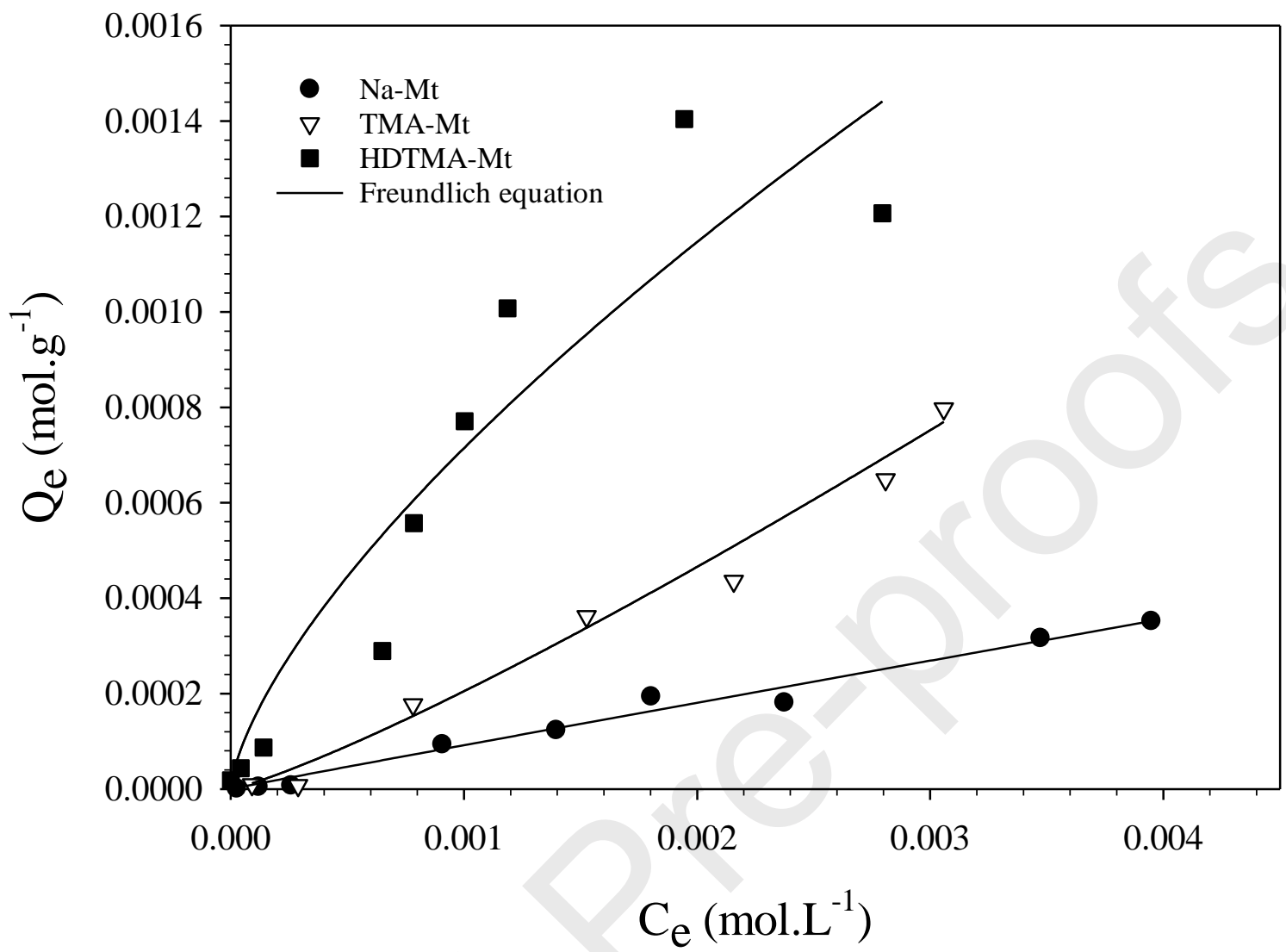

Fig. 4. Adsorption isotherms at the equilibrium of the batch adsorption experiments of the AMX onto Na-Mt, TMA-Mt and HDTMA-Mt and their fitting with the use of a Freundlich model. 


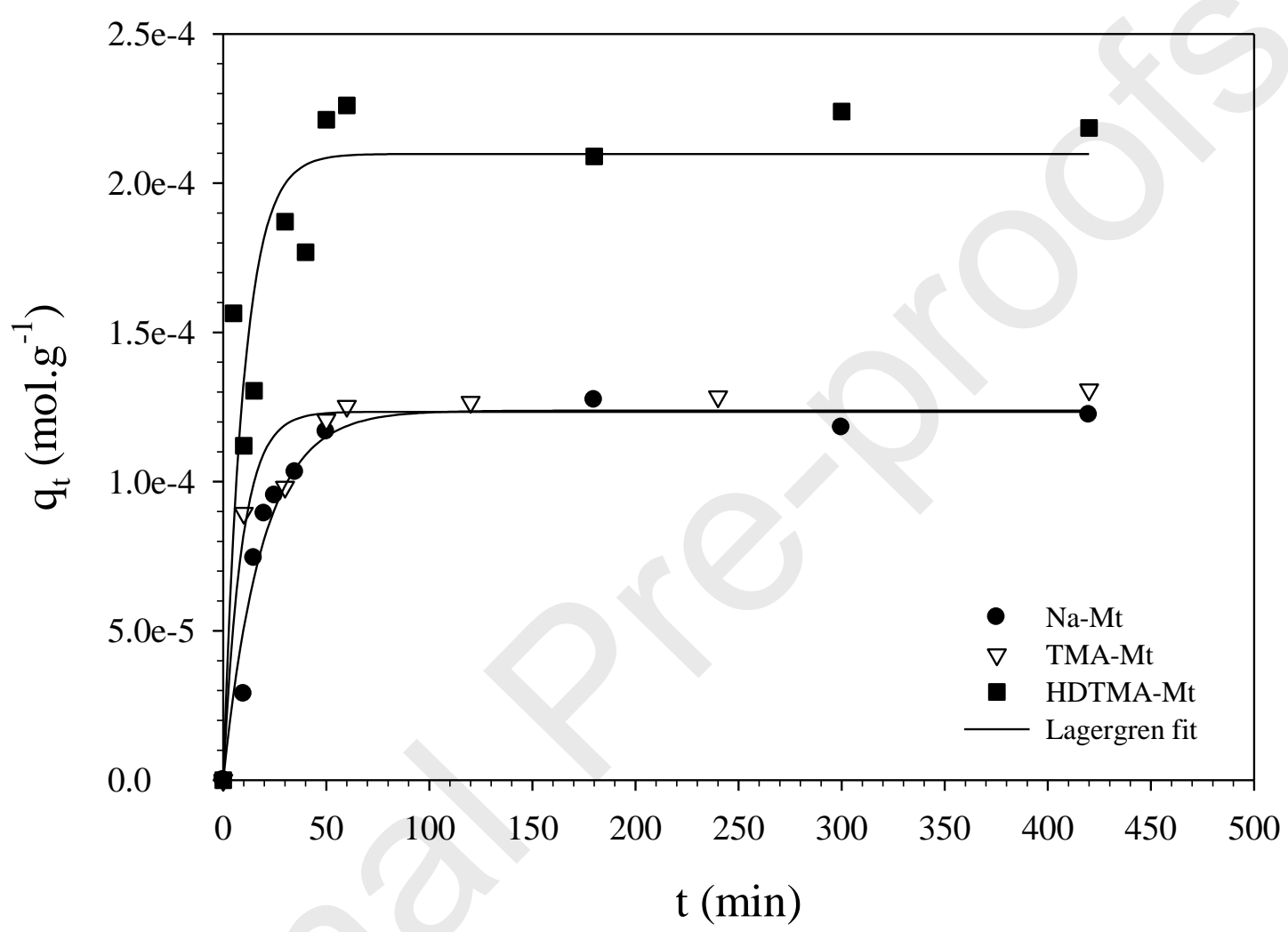

Fig. 5. Kinetics adsorption isotherms of the batch adsorption experiments of the AMX onto Na-Mt, TMA-Mt and HDTMA-Mt and their fitting with the use of a pseudo-first order model. 


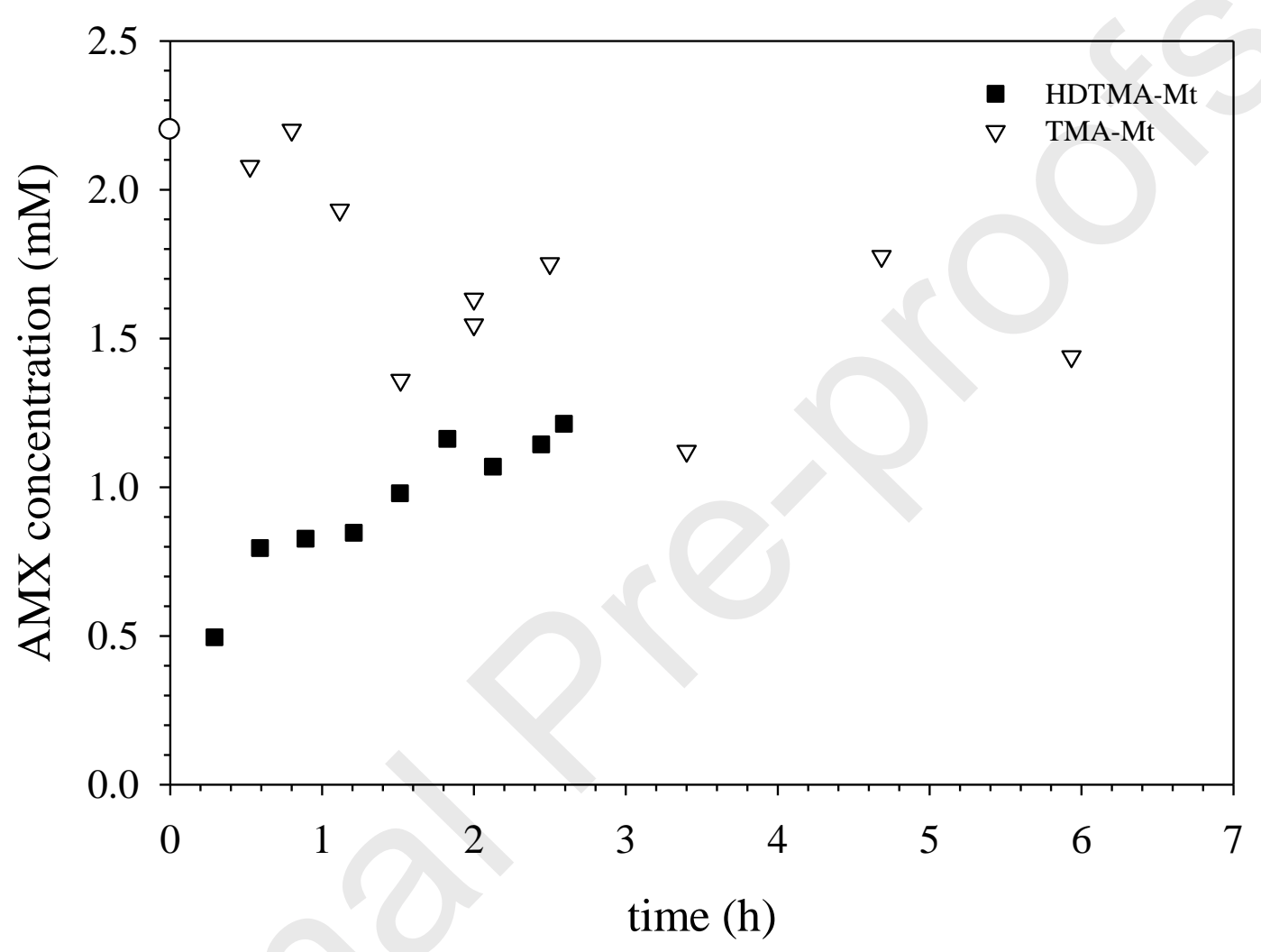

Fig. 6. Evolution of the concentration of AMX in the leachates collected after a percolation experiment through both TMA-Mt and HDTMA-Mt used as geo-sorbents with a solution of AMX at a concentration of $800 \mathrm{mg} \mathrm{L}^{-1}$. The data of Na-Mt, with its low conductivity for water, are not shown since no leachate could be collected within the same time window. 


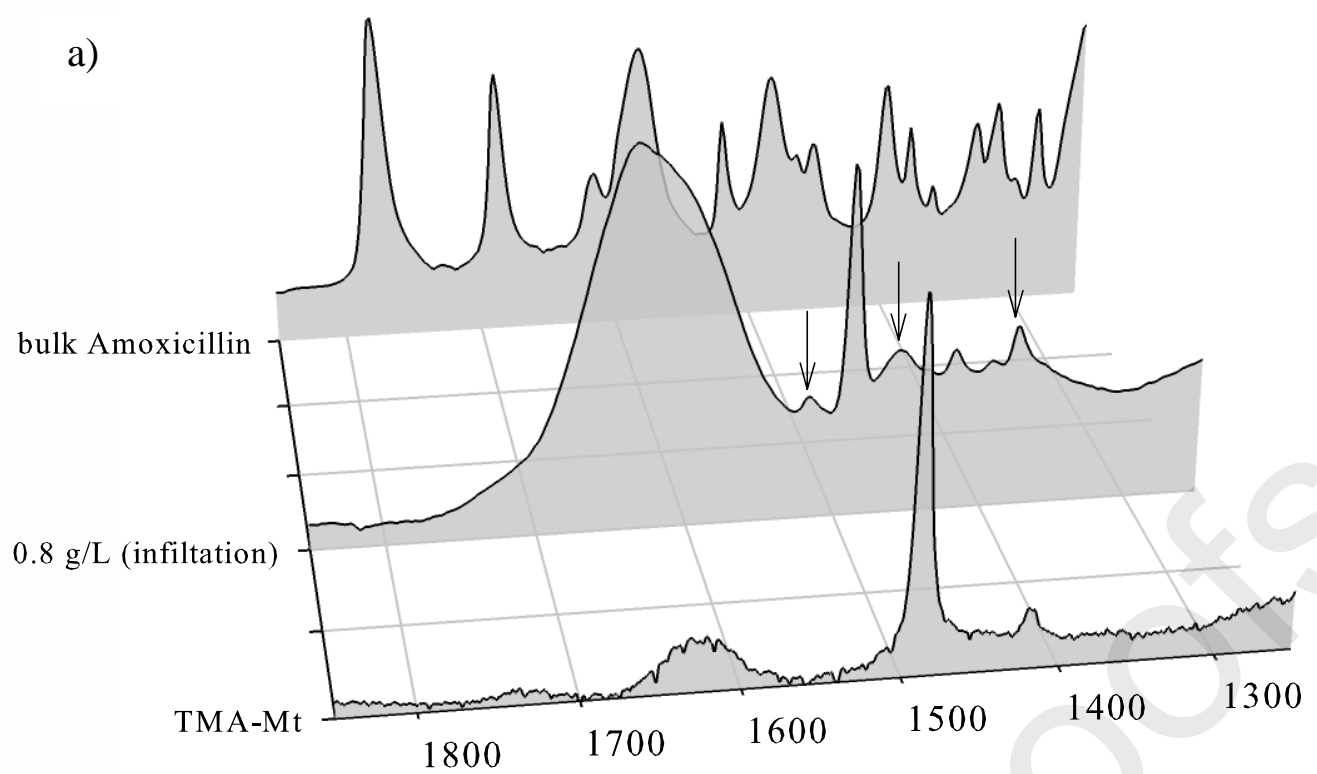

$v\left(\mathrm{~cm}^{-1}\right)$

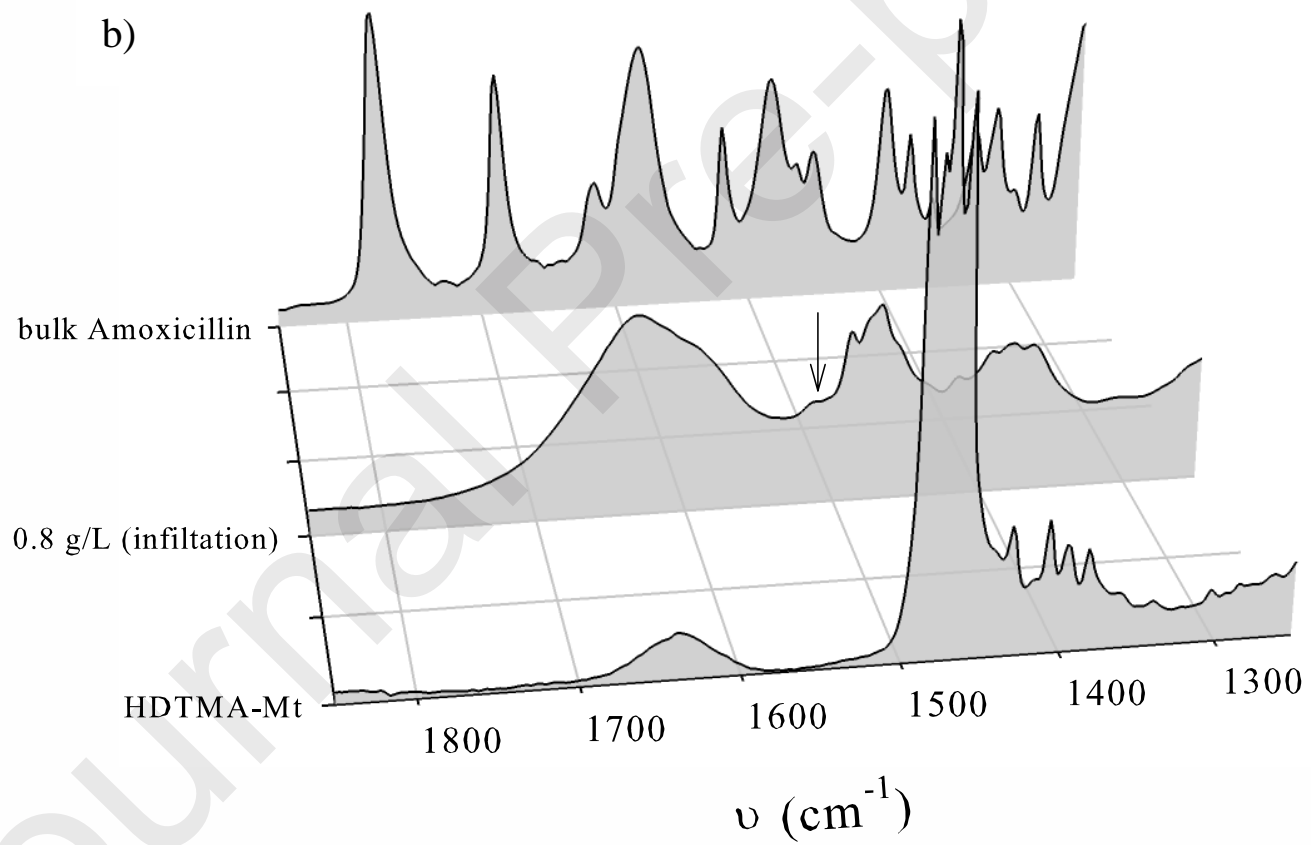

Fig. 7. 3D evolution of the FTIR spectra in the $1850-1300 \mathrm{~cm}^{-1}$ wavenumbers range (probing the $\mathrm{COO}^{-}$absorption bands and $\mathrm{CH}$ deformation bands) of (a) TMA-Mt and (b) HDTMA-Mt before and after a percolation experiment with a solution of AMX at a concentration of $800 \mathrm{mg} \mathrm{L} \mathrm{L}^{-1}$. The presence of AMX onto the layered materials is emphasized by arrows pointing at the vibration bands related to the antibiotics. 


\section{Highlights}

In batch conditions, organoclays display outstanding adsorption properties for amoxicillin The hydraulic conductivity of organoclays mainly depends on their organic content The hydraulic conductivity of organoclays appears insufficient to retain the amoxicillin The poor retention behavior of organoclays tunes down their environmental interests 